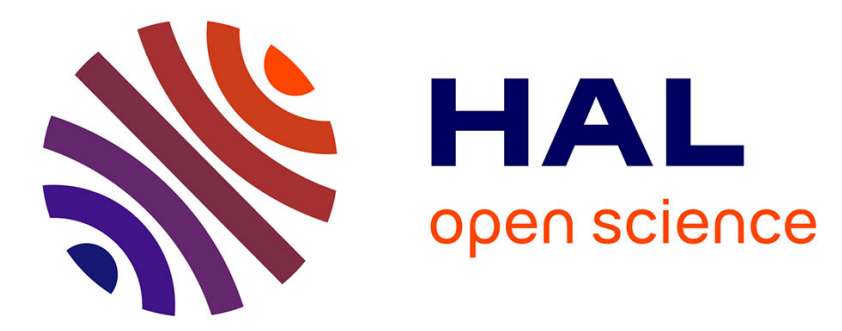

\title{
Detecting short spatial scale local adaptation and epistatic selection in climate-related candidate genes in European beech (Fagus sylvatica) populations
}

Katalin Csilléry, Hadrien Lalagüe, Giovanni Giuseppe Vendramin, Santiago C. González-Martínez, Bruno Fady, Sylvie Oddou-Muratorio

\section{To cite this version:}

Katalin Csilléry, Hadrien Lalagüe, Giovanni Giuseppe Vendramin, Santiago C. González-Martínez, Bruno Fady, et al.. Detecting short spatial scale local adaptation and epistatic selection in climaterelated candidate genes in European beech (Fagus sylvatica) populations. Molecular Ecology, 2014, 23 (19), pp.4696-4708. 10.1111/mec.12902 . hal-02640214

\section{HAL Id: hal-02640214 \\ https://hal.inrae.fr/hal-02640214}

Submitted on 28 May 2020

HAL is a multi-disciplinary open access archive for the deposit and dissemination of scientific research documents, whether they are published or not. The documents may come from teaching and research institutions in France or abroad, or from public or private research centers.
L'archive ouverte pluridisciplinaire HAL, est destinée au dépôt et à la diffusion de documents scientifiques de niveau recherche, publiés ou non, émanant des établissements d'enseignement et de recherche français ou étrangers, des laboratoires publics ou privés. 
Version définitive du manuscrit publiée dans / Final version of the manuscript published in :

Molecular Ecology (2014), DOI: 10.1111/mec.12902

Journal homepage: http:/lonlinelibrary.wiley.com/doi/10.1111/mec.12902/abstract

Received Date : 16-Aug-2012

Revised Date : 20-Aug-2014

Accepted Date : 22-Aug-2014

Article type : Original Article

Title: Detecting short spatial scale local adaptation and epistatic selection in climate-related candidate genes in European beech (Fagus sylvatica) populations.

Running title: Local adaptation and epistatic selection in beech

Authors: Katalin Csilléry ${ }^{1, \S}$, Hadrien Lalagüie ${ }^{1,2,3, \S}$, Giovanni G. Vendramin ${ }^{3}$, Santiago C. González-Martínez ${ }^{4}$, Bruno Fady ${ }^{1}$ and Sylvie Oddou-Muratorio ${ }^{1 *}$

\section{$\S$ These two authors contributed equally}

\section{Addresses:}

1 UR629, Écologie Forestière Méditerranéenne, INRA, Domaine Saint Paul, F-84914 Avignon, France.

${ }^{2}$ Scuola Superiore Sant'Anna, Piazza Martiri della Libertà 33, 56127 Pisa, Italy.

${ }^{3}$ CNR, Institute of Bisciences and Bioresources, Via Madonna del Piano 10, 50019 Sesto Fiorentino (Firenze), Italy.

${ }^{4}$ CIFOR-INIA, Forest Research Centre, Carretera de La Coruña km 7.5, 28040, Madrid, Spain.

This article has been accepted for publication and undergone full peer review but has not been through the copyediting, typesetting, pagination and proofreading process, which may lead to differences between this version and the Version of Record. Please cite this article as doi: $10.1111 /$ mec. 12902

This article is protected by copyright. All rights reserved. 
Version définitive du manuscrit publiée dans / Final version of the manuscript published in :

Molecular Ecology (2014), DOI: 10.1111/mec.12902

Journal homepage: http://onlinelibrary.wiley.com/doi/10.1111/mec.12902/abstract

\title{
*Corresponding author
}

Sylvie Oddou-Muratorio

INRA, Unité de Recherches Forestières Méditerranéennes

Domaine Saint Paul, Site Agroparc

84914 Avignon Cedex 9, France

Fax: +33 (0)4 32722902

oddou@avignon.inra.fr

SOM, GGV, and BF designed the experiments. HL performed all bioinformatic analysis (ORF determination), the simulation of demographic scenarios with the help of SCGM, and identified the functional role of genes under selection. KC and SOM performed all other statistical analyses. KC and SOM wrote the paper (and HL the initial draft). All authors contributed to data interpretation and revisions of the manuscript.

Key-words: $F_{S T}$ outlier, haplotype, variance components of linkage disequilibrium, Ohta's test, gene network, budburst phenology, abiotic stress

\begin{abstract}
Detecting signatures of selection in tree populations threatened by climate change is currently a major research priority. Here, we investigated the signature of local adaptation over a short spatial scale using 96 European beech (Fagus sylvatica L.) individuals originating from two pairs of populations on the northern and southern slopes of Mont Ventoux (south-eastern France). We performed both single and multi-locus analysis of selection based on 53 climaterelated candidate genes containing 546 SNPs. $F_{S T}$ outlier methods at the SNP level revealed a
\end{abstract}

This article is protected by copyright. All rights reserved. 
Version définitive du manuscrit publiée dans / Final version of the manuscript published in :

Molecular Ecology (2014), DOI: 10.1111/mec.12902

Journal homepage: http:/lonlinelibrary.wiley.com/doi/10.1111/mec.12902/abstract

weak signal of selection, with three marginally significant outliers in the northern populations. At the gene-level, considering haplotypes as alleles, two additional marginally significant outliers were detected, one on each slope. To account for the uncertainty of haplotype inference, we averaged the Bayes Factors over many possible phase reconstructions. Epistatic selection offers a realistic multi-locus model of selection in natural populations. Here, we used a test suggested by Ohta based on the decomposition of the variance of linkage disequilibrium. Over all populations, $0.23 \%$ of the SNP pairs (haplotypes) showed evidence of epistatic selection, with nearly $80 \%$ of them being within genes. One of the between gene epistatic selection signals arose between an $F_{S T}$ outlier and a nonsynonymous mutation in a drought response gene. Additionally, we identified haplotypes containing selectively advantageous allele combinations which were unique to high or lowelevations and northern or southern populations. Several haplotypes contained nonsynonymous mutations situated in genes with known functional importance for adaptation to climatic factors.

\section{INTRODUCTION}

Spatially variable selection plays a crucial role in shaping phenotypic variation within and among natural populations. Local adaptation occurs when populations distributed across heterogeneous environments evolve different phenotypic trait values conferring fitness advantage in their local environment (Le Corre \& Kremer, 2003; Schoville et al. 2012). Increasing concerns regarding climate change have renewed the interest in estimating species adaptive capacity under spatially variable selection in the hope of better understanding shortterm potential for evolutionary responses (Hansen et al. 2012). Forest trees play a key role in this context: they cover approximately three quarters of the earth's terrestrial biomass and are often keystone species in their habitats. Furthermore, tree species are ideal case studies for

This article is protected by copyright. All rights reserved. 
Version définitive du manuscrit publiée dans / Final version of the manuscript published in :

Molecular Ecology (2014), DOI: 10.1111/mec.12902

Journal homepage: http:/lonlinelibrary.wiley.com/doi/10.1111/mec.12902/abstract

detecting selection in natural populations because they have large effective population sizes, where selection is expected to be efficient, and demonstrate weak neutral genetic differentiation even over large geographic ranges, which decreases the chance of confusing the effects of selection and population structure (Savolainen \& Pyhäjärvi, 2007).

The existence of locally adapted forest tree populations has long been suggested based on several lines of evidence. First, phenotypic clines along environmental gradients are common in forest trees (typically for phenological traits) and the triggering of major adaptive traits by climatic clues is often prescribed to selection (Mikola, 1982). Second, forest geneticists have long been conducting semi-controlled transplantation experiments, so-called provenance tests, which often demonstrate strong latitudinal genetic clines for potentially adaptive traits such as bud set, cold tolerance, growth or photoperiod sensitivity (Alberto et al. 2013a).

Third, more recently, using genomic tools developed for forest tree species (Neale \& Kremer, 2011; Kremer et al. 2012), several studies corroborate the evidence of adaptive genetic differentiation among tree populations along environmental gradients (Eveno et al. 2008; Ma et al. 2010; Chen et al. 2012; Kujala \& Savolainen, 2012; Alberto et al. 2013b; Mosca et al. 2014).

The detection of molecular imprints of local adaptation, however, has been recently challenged by several authors both from methodological and biological points of view (e.g. Pritchard et al. 2010; Le Corre \& Kremer, 2012). Among the most commonly used methods, the so-called $F_{S T}$ outlier tests are based on the idea that loci under divergent or homogenizing selection are expected to have unusually high or low levels of differentiation between populations, respectively (e.g. Beaumont and Nichols 1996). Several recent simulation studies suggested that these $F_{S T}$ outlier tests can have a high rate of false positives and lack

This article is protected by copyright. All rights reserved. 
power (Excoffier et al. 2009; Vilas et al. 2012; De Mita et al. 2013; Lotterhos \& Whitlock, 2014). From a methodological point of view, this is because, first, $F_{S T}$ outlier tests assume a demographic model that is often far from the reality (Excoffier et al. 2009; Lotterhos \& Whitlock, 2014), and, second, $F_{S T}$ outlier tests are often applied to insufficient or inappropriate data (Foll \& Gaggiotti 2008). For example, in the case of candidate gene data, the presence of linked loci within genes decreases the effective number of loci (Vilas et al. 2012). From a biological point of view, the genetic architecture of adaptive traits in natural populations is complex and probably influenced by many loci simultaneously (e.g. Mackay, 2014), thus looking for the signature of selection at individual loci is rather naive. Therefore, more realistic mechanisms of evolutionary change, such as polygenic and epistatic selection, need to be considered in selection tests (Fu \& Akey, 2013); so far, however, methodological developments are lagging behind.

Polygenic adaptation in natural populations can be reached via weak allele frequency changes at multiple loci across the genome, where advantageous alleles exist at low to moderate frequencies (Pritchard et al. 2010; Fu \& Akey, 2013). Le Corre \& Kremer (2003) proposed a theoretical framework to predict polygenic adaptation, and showed that adaptive phenotypic divergence in response to polygenic selection (traditionally measured by $Q_{S T}$ ) is first achieved through the filtering of combinations of advantageous alleles at multiple loci (typically in $<10$ generations), while changes in allele frequencies occur later (increasing $F_{S T}$ ). Polygenic adaptation may be estimated as the covariance of allele frequencies among populations, i.e. the between-population variance component of the total linkage disequilibrium (the so-called $D_{S T}$ in Ohta, 1982 or Zg in Storz \& Kelly, 2008). In practice, Storz \& Kelly (2008) showed that the $\mathrm{Zg}$ of 11 alpha-globin genes, known to contribute to differences in aerobic capacity between mice populations from low and high elevations, was significantly higher than 
Version définitive du manuscrit publiée dans / Final version of the manuscript published in :

Molecular Ecology (2014), DOI: 10.1111/mec.12902

Journal homepage: http:/lonlinelibrary.wiley.com/doi/10.1111/mec.12902/abstract

expected from a simulated sample of neutral genes. In another study, Ma et al. (2010) showed that the covariance of allelic effects was higher for photoperiodic genes than for control genes in Populus tremula, and that most of the observed phenotypic variation was explained by the covariance among individual locus effects and not by individual SNPs.

Methodological developments to detect epistatic selection in natural populations are also lagging behind (Fu \& Akey, 2013; Hansen, 2013). Ohta (1982) proposed four statistics based on the decomposition of the variance of linkage disequilibrium (LD) that may be used to test if LD between two loci is due to drift (or linkage) or epistatic selection. She argued that if epistatic selection is responsible for LD, haplotypes with favorable combinations of alleles would become frequent in every sub-population. Thus, in comparison to the test of local adaptation based on the between population component of the variance of LD (Le Corre \& Kremer, 2003; Storz \& Kelly, 2008), Ohta's test can be viewed as its opposite: while the former aims at identifying haplotypes with unusually high $D_{S T}$ values, the latter is looking for unusually low $D_{S T}$ values. An important technical difference between the two tests is that while unusually high $D_{S T}$ values can only be identified using a genomic control (typically using supposedly neutral loci), unusually low $D_{S T}$ values can be identified by comparing $D_{S T}$ to the gametic phase equilibrium of the same loci. Despite its conceptual simplicity, Ohta's test has rarely been applied to experimental data, especially to recent genetic data (but for tests on allozyme data in forest trees, see Cheng et al. 2001; Fernández-López \& Monteagudo, 2010).

Here, we investigated the signatures of local adaptation and epistatic selection at a local scale from candidate gene data in European beech (Fagus sylvatica), a dominant tree species of

This article is protected by copyright. All rights reserved. 
many lowland forests across Europe. Genetic differentiation along local elevational gradients has been previously reported in $F$. sylvatica for various traits related to climate response, including phenology of budburst (Vitasse et al. 2009), leaf mass per area (LMA), nitrogen content and leaf size (Bresson et al. 2012). Nevertheless, so far, only a few published studies attempted to detect the molecular signature of divergent selection in F. sylvatica. First, using AFLP genome scans along an elevational gradient, Jump et al. (2006) identified one outlier locus (among 241 scored) and showed that the gene frequency at this locus was correlated with mean annual temperature. Second, using again AFLP genome scans and 3 replicated pairs of mesic and dry sites, Pluess \& Weber (2012) detected 13 outlier loci (among 517 scored), from which 7 changed their frequencies with local moisture availability. Three climate-related candidate genes datasets were recently developed for $F$. sylvatica (Seifert et al. 2012; Muller 2013; Lalagüe et al. 2014), but their potential has not yet been fully exploited to investigate the signature of local adaptation.

We sampled 96 individuals from two pairs of populations situated on the northern and southern slopes of Mont Ventoux (south-eastern France). This sampling design ensured sharp environmental differences across elevations at short spatial scale, favorable for the detection of recent selection (Alberto et al. 2013b; Körner, 2007). We used 53 candidate genes potentially involved in climate response (Lalaguie et al. 2014) to investigate signatures of selection both at single- and multi-locus levels. At the single-locus level, we used $F_{S T}$ outlier methods for both SNPs and genes. Following Eveno et al. (2008), we used $F_{S T}$ outlier tests for entire genes to account for non-independence among loci and we additionally proposed an averaging Bayesian model to take into account the uncertainty of haplotype inference when the haplotype phase is unknown. At the multi-locus level, we applied Ohta's test of epistatic selection, for the first time, to candidate gene data. We paid particular attention to the 
Version définitive du manuscrit publiée dans / Final version of the manuscript published in :

Molecular Ecology (2014), DOI: 10.1111/mec.12902

Journal homepage: http:/lonlinelibrary.wiley.com/doi/10.1111/mec.12902/abstract

functional genomic interpretation of haplotypes showing evidence for epistatic selection, and illustrated the advantage of combining different approaches and data to detect signatures of selection.

\section{Materials AND Methods}

\section{Sampling and populations}

Fagus sylvatica populations on Mont Ventoux originate from a common Holocene gene pool (Magri et al. 2006). In the 17th century, they went through a bottleneck, where only four remnant populations survived at high elevations (Lander et al. 2011). Since then, following changes in land-use, F. sylvatica recurrently re-colonised Mont Ventoux from the remnant populations. At microsatellite loci, a low, but significant genetic differentiation was shown between the northern and southern slopes $\left(F_{C T}=0.2 \%\right)$, and among populations within each slope $\left(F_{S C}=2.5 \%\right.$; Lander et al. 2011).

We used the candidate gene dataset previously described in Lalagüe et al. (2014) for all analyses presented in this paper. The dataset comprised 96 individuals from four populations; two situated on the northern slope (high -NH- and low -NL- with 35 and 36 individuals, respectively) and two on the southern slope (high -SH- and low -SL- with 12 and 13 individuals, respectively) (see Fig. 1). Individuals from the NH, NL, and SH sites represent remnant populations, while the SL site has recently been colonized by $F$. sylvatica. Local measurements of temperature, relative humidity and precipitation at the four sampling sites over five years revealed that climatic conditions differ between high and low elevation populations both at the northern and southern slopes (Table 1). Accordingly, phenotypic and genotypic differences have been demonstrated between NH and NL populations for the date

This article is protected by copyright. All rights reserved. 
Version définitive du manuscrit publiée dans / Final version of the manuscript published in :

Molecular Ecology (2014), DOI: 10.1111/mec.12902

Journal homepage: http:/lonlinelibrary.wiley.com/doi/10.1111/mec.12902/abstract

of budburst (nine days lag, Gauzëre et al., 2013; $Q_{\mathrm{ST}}=5 \%$ for populations located less than one km apart, J. Gaüzere, pers comm).

\section{Genetic data and functional annotation}

A reduced version of the candidate gene dataset described in Lalagüe et al. (2014) was generated for this study, by removing four duplicate genes (see supporting information ESM1 of Lalagüe et al. 2014). The new dataset comprises 546 SNPs from 53 candidate genes (Table S1, Supporting information) that are potentially involved in response to abiotic stress (e.g. drought or frosts) and phenology (e.g. bud-burst). Note that the full-length sequences of these candidate genes were generally not available, but only gene fragments. We determined the open reading frames $(\mathrm{ORF})$ and the intron-exon boundaries of the 53 candidate genes by comparing F. sylvatica Expressed Sequence Tags (ESTs) with proteins of related species available in the NCBI Reference Sequence (RefSeq) or non-redundant (nr) databases in May 2013. To perform these analyses, we used CodonCode Aligner v3.7.1 (CodonCode Corporation, http://www.codoncode.com) and BLASTX (Altschul et al. 1990) with default parameters. We also determined whether changes in SNPs located within exons were synonymous or non-synonymous. In total, 235 SNPs were found in exons, with 82 coding for non-synonymous and 153 for synonymous mutations; 262 SNPs were found in introns, 30 in 3'UTR and 1 in 5'UTR regions (Table S2, Supporting information).

\section{Haplotype inference}

We used PHASE version 2.1 (Stephens \& Donnelly, 2003) to simultaneously impute the missing genotypes at each SNP, infer the phase and estimate the haplotype frequencies for each gene independently. We used the MR0 model with varying recombination rate (Li \& Stephens, 2003) and probability thresholds of 0.95 for both missing alleles and phase

This article is protected by copyright. All rights reserved. 
Version définitive du manuscrit publiée dans / Final version of the manuscript published in :

Molecular Ecology (2014), DOI: 10.1111/mec.12902

Journal homepage: http://onlinelibrary.wiley.com/doi/10.1111/mec.12902/abstract

inference. We ran five independent Markov chains of length $10^{4}$, with a thinning interval of 10 and a burn-in period of $10^{4}$. Using PHASE the original rate of missing data of $24.6 \%$ was decreased to $12.1 \%$ in the imputed and to $12.4 \%$ in the phased datasets. Further, we used the s option of PHASE to draw $10^{3}$ samples from the posterior distribution of the haplotypes, i.e. $10^{3}$ different realizations of the phased dataset where all missing data were replaced by a “best guess" haplotype. To calculate Ohta's LD statistics between SNPs situated in different genes, we used the EM algorithm implemented in the $\mathrm{R}$ package haplo.stat (http://www.mayo.edu/research/labs/statistical-genetics-genetic-epidemiology/software) to infer the haplotype phase. To summarize, we used three different versions of the dataset for further analysis (each based on 546 SNPs): imputed genotype data, phased data, and bestguess haplotype samples $\left(10^{3}\right.$ realizations). For all analyses except the calculation of $F_{S T}$ and hierarchical AMOVA, loci with more than $30 \%$ missing data were removed from the imputed and phased datasets, leaving 483 and 481 SNPs, respectively, for further analysis.

\section{Genetic differentiation and $\boldsymbol{F}_{S T}$ outlier tests}

$F_{S T}$ (Weir \& Cockerham, 1984) between populations was estimated both at the SNP and gene levels using the imputed genotype and phased data, respectively. Components of the variance in allele frequencies within and between the northern and southern population pairs were estimated using the hierarchical AMOVA implemented in Arlequin v.3.5.1.3 (Excoffier et al. 1992).

We used the $F_{S T}$ outlier methods to detect selection due to climatic stress induced by elevational differences (Table 1). We tested two scenarios. First, we considered the northern and southern slopes as replicates for elevation-related climatic stress; second, we considered the four populations in a hierarchical model (i.e. two populations nested within northern and This article is protected by copyright. All rights reserved. 
Version définitive du manuscrit publiée dans / Final version of the manuscript published in :

Molecular Ecology (2014), DOI: 10.1111/mec.12902

Journal homepage: http:/lonlinelibrary.wiley.com/doi/10.1111/mec.12902/abstract

southern slopes). Thus, the latter also accounted both for hierarchical genetic structure and for the marked differences between the two slopes themselves (Table 1). Overall, we expected to detect few $F_{S T}$ outlier loci because gene flow is high between our sampled populations and because outlier detection methods lack power when few populations are tested (Foll \& Gaggiotti, 2008). We looked for both unusually differentiated SNPs and genes.

At the SNP level, we used the $F_{S T}$ outlier methods of Beaumont \& Nichols (1996) and Foll \& Gaggiotti (2008) implemented in Arlequin v.3.5.1.3 and BayeScan 2.1, respectively. We used the imputed genotype data, and removed loci with a minor allele frequency (MAF) below 0.05 (leaving 307 SNPs to analyze). In the Beaumont \& Nichols (1996) approach, the expected neutral $F_{S T}$ distribution was obtained by simulating $10^{5}$ SNPs under a hierarchical island model (with 10 groups and 10 demes per group). The target $F_{S T}$ was estimated from all SNPs, assuming that the majority of them were neutral. The $p$-values obtained from Arlequin were corrected for multiple testing using the False Discovery Rate (FDR) method of the function "p.adjust" in R (package stats; R Development Team 2011). Further, we investigated the sensitivity of the Beaumont \& Nichols (1996) method to the demography assumed by the null model. We used information from the well-documented demographic history of European beech on Mont Ventoux (Lander et al. 2011) to simulate more realistic alternative null models using ms (Hudson, 2002; Appendix S1, Supporting information). In the Foll \& Gaggiotti (2008) method, we used Bayes Factors to evaluate the evidence for selection, based on Jeffreys' scale of evidence. BayeScan was run with 20 pilot runs of 5,000 iterations and then a burn-in of 50,000 iterations followed by 50,000 iterations (thinning interval of 10). Since the probability of being under selection is higher for a SNP situated in a candidate gene than for a random SNP, we decreased the prior odds for the null model from 10 (default) to 2 (M. Foll, pers. comm.). Further, we investigated the sensitivity of BayeScan

This article is protected by copyright. All rights reserved. 
Version définitive du manuscrit publiée dans / Final version of the manuscript published in :

Molecular Ecology (2014), DOI: 10.1111/mec.12902

Journal homepage: http:/lonlinelibrary.wiley.com/doi/10.1111/mec.12902/abstract

to the MAF level (Appendix S2, Supporting information). Note that there was no hierarchical model implemented in BayeScan when this study was done.

We also performed an $F_{S T}$ outlier test at the level of genes following Eveno et al. (2008), where each gene was considered as a multi-allelic locus. In contrast to Eveno (2008), the haplotype phase was unknown, so we had to rely on estimates from PHASE. We only used the Foll \& Gaggiotti (2008) approach. BayeScan was run for each of the $10^{3}$ different bestguess haplotype samples, and the median $\log 10$ Bayes Factor was used to summarize the overall evidence for selection.

\section{Epistatic selection}

We used Ohta's test (1982) to detect epistatic selection, which is based on the decomposition of the variance of linkage disequilibrium (LD) within a subdivided population into within $\left(\mathrm{D}_{\mathrm{IS}}{ }^{2}\right)$ and between population $\left(\mathrm{D}_{\mathrm{ST}}{ }^{2}\right)$ components. When epistatic selection is responsible for LD, haplotypes with favorable combinations of alleles are expected to increase in all populations, i.e. $\mathrm{D}_{\mathrm{ST}}{ }^{2}<\mathrm{D}_{\mathrm{IS}}{ }^{2}$. In contrast, if the observed LD is a consequence of genetic drift and limited migration between sub-populations, the expected variance of LD within subpopulations should be smaller than the variance in the expected frequencies of different gametes. Ohta defined two further variance components: $\mathrm{D}_{\mathrm{IS}}{ }^{2}$ is the variance of the correlation of genes of the two loci of one gamete in a sub-population relative to that of the total population and $\mathrm{D}_{\mathrm{ST}}{ }^{2}$ is the variance of $\mathrm{LD}$ of the total population. According to Ohta (1982), epistatic selection is responsible for LD if $\mathrm{D}_{\mathrm{ST}}{ }^{2}<\mathrm{D}_{\mathrm{IS}}{ }^{2}$ and $\mathrm{D}_{\mathrm{IS}}^{\prime}{ }^{2}<\mathrm{D}_{\mathrm{ST}}^{\prime}{ }^{2}$. Here, $\mathrm{D}_{\mathrm{IS}}^{\prime}{ }^{2}$ was obtained as $\mathrm{D}_{\mathrm{IT}}{ }^{2}-\mathrm{D}_{\mathrm{ST}}{ }^{2}$ (equation 16 in Ohta 1982), where $\mathrm{D}_{\mathrm{IT}}^{2}$ depends only on the haplotype frequencies of the sub-populations.

This article is protected by copyright. All rights reserved. 
Version définitive du manuscrit publiée dans / Final version of the manuscript published in :

Molecular Ecology (2014), DOI: 10.1111/mec.12902

Journal homepage: http:/lonlinelibrary.wiley.com/doi/10.1111/mec.12902/abstract

First, we performed Ohta's test for all four populations combined to identify SNP pairs (haplotypes) that systematically carry favorable combinations of alleles in any environments (i.e. any exposition and elevation). These SNP pairs thus show a global evidence of epistatic selection. Second, we applied Ohta's test only to the two northern or two southern populations, and to the two high or two low elevation populations. Haplotypes with selectively favored allele combinations that were unique to northern and southern populations, or to low or high elevations were interpreted as climate-specific signatures of epistatic selection. In both cases, we used the intron/exon status and the synonymous or nonsynonymous state of the SNPs located in exons to screen Ohta's test results for loci with a potential functional role.

Among the 481 SNPs of the phased dataset, 115,440 pairwise comparisons were possible. However, we did not perform Ohta's test if (i) a population had only missing data, (ii) a locus was not polymorphic at least in one of the populations, (iii) more than half of the individuals had missing gametes in at least one of the populations. As a result, between $63 \%$ and $76 \%$ of the pairwise comparisons between SNPs were removed depending on the scenario tested (Table 2). Further, some complete genes were lost (i.e. all of their SNPs were excluded).

Since our sample sizes were relatively small and Ohta's test strongly relies on phase reconstruction (i.e. the haplotype frequencies), we used the $10^{3}$ different best-guess haplotype samples to test the robustness of Ohta's test to the haplotype inference. In these analyses, although there were no missing data (all missing data were replaced by a best guess that varies from one dataset to another), we nevertheless only tested SNP pairs that were present in the original dataset. We accepted an epistatic interaction as "stable" if it passed Ohta's test in at least $95 \%$ of the different best-guess haplotype samples.

This article is protected by copyright. All rights reserved. 
Version définitive du manuscrit publiée dans / Final version of the manuscript published in :

Molecular Ecology (2014), DOI: 10.1111/mec.12902

Journal homepage: http:/lonlinelibrary.wiley.com/doi/10.1111/mec.12902/abstract

\section{RESULTS}

\section{Genetic differentiation}

The average genetic differentiation measured by $F_{S T}$ on the northern and southern slopes, respectively, was 0.017 and 0.013 at the SNP level and 0.015 and 0.012 at the gene level (Fig. S1, Supporting information). The hierarchical AMOVA confirmed the existence of a significant genetic differentiation among populations within the northern and southern slopes $\left(F_{S C}=0.02\right.$ at the SNP level and $F_{S C}=0.015$ at the gene level), and between the slopes at the gene level $\left(F_{C T}=0.006\right)$, but not at the SNP level $\left(F_{C T}=-0.001\right)$ (Table S3, Supporting information). Gene specific $F_{S T}$ showed a mild variation between genes, with 14 and 4 genes showing a significant differentiation on the northern and southern slopes, respectively (Fig. S1).

\section{$F_{S T}$ outlier tests}

The hierarchical model of Arlequin detected two outlier SNPs: one at position 450 in gene 88_1 $\left(F_{S T}=0.30, \mathrm{q}\right.$-value $\left.<0.0001\right)$ and the other at position 787 in gene $23 \_1\left(F_{S T}=0.27\right.$, qvalue $<0.0001$ ). When we tested for outlier SNPs using different demographic models accounting for the recent $F$. sylvatica population expansion, we found that the constant size island model was always the most conservative (Appendix S1). When accounting for more realistic demographic scenarios, additional outlier SNPs were revealed; notably, the strongest evidence was found for the SNP at position 328 in gene 142. No outliers were detected using Arlequin when testing the northern and southern slopes separately. Using BayeScan, in agreement with Arlequin, we found evidence for divergent selection for the (position 787) SNP in gene 23_1 and marginal evidence for the (position 328) SNP in gene 142, in the northern populations (Fig. 2A). We found that BayeScan was little sensitive to the MAF

This article is protected by copyright. All rights reserved. 
Version définitive du manuscrit publiée dans / Final version of the manuscript published in :

Molecular Ecology (2014), DOI: 10.1111/mec.12902

Journal homepage: http:/lonlinelibrary.wiley.com/doi/10.1111/mec.12902/abstract

criteria (Appendix S2): (i) the same two outlier loci were confirmed across the three MAF criteria tested and (ii) the greater the MAF was, the stronger the evidence was. None of the SNP-level outliers coded for non-synonymous mutations or were located in 3'UTR regions.

BayeScan at gene level displayed an extreme sensitivity to phase reconstruction (Fig. 2C-F): the Bayes Factor varied from nearly 0 to over 20 depending on the phase reconstruction. Using the median $\log 10$ Bayes Factor as a summary over the $10^{3}$ different best-guess haplotype samples, gene 134_2_2 showed a weak signal of homogenizing selection in the northern populations (Fig. 2B and E) and gene 58 a weak signal of divergent selection in the southern populations (Fig. 2E and F). Further, the two genes that contained an outlier SNP also showed a weak signal of selection at the gene level: gene 23_1 revealed a weak signal of homogenizing selection (Fig. 2C) and gene 142 a weak signal of divergent selection (Fig. 2D).

\section{Epistatic selection}

The two conditions of Ohta's test were satisfied for less than $0.5 \%$ percent of the SNP pairs (Table 2). The condition $\mathrm{D}_{\mathrm{ST}}{ }^{2}<\mathrm{D}_{\mathrm{IS}}{ }^{2}$ was satisfied more than two times more frequently than $\mathrm{D}_{\mathrm{IS}}^{\prime}{ }^{2}<\mathrm{D}_{\mathrm{ST}}{ }^{2}$, which may be because the variance components that depend only on the allele frequencies $\left(\mathrm{D}_{\mathrm{ST}}^{2}\right)$ can be estimated with more confidence. Across the $10^{3}$ different estimates of the haplotype frequencies, Ohta's test performed consistently: overall, between 63 (south) and 90 (all populations) percent of the SNP pairs that initially passed the test in the phased dataset showed consistent evidence in over $95 \%$ of the best-guess haplotype samples (Table 2).

This article is protected by copyright. All rights reserved. 
Version définitive du manuscrit publiée dans / Final version of the manuscript published in :

Molecular Ecology (2014), DOI: 10.1111/mec.12902

Journal homepage: http://onlinelibrary.wiley.com/doi/10.1111/mec.12902/abstract

We found evidence for epistatic selection in $0.23 \%$ of all SNP pairs across the four populations (Table 2, column «All ). Nearly $80 \%$ of them represented SNP pairs within the same gene, from 15 unique genes. Some of them involved SNPs coding for non-synonymous mutations or SNPs in 3'UTR regions (genes 20, 39, 68, 110, 52_1, Table S4, Supporting information). Two of the three between-gene interactions were found between genes of similar function, i.e. between the two catalase 3 coding genes (91_2 and 98_1) and between the two adenosyl-homocysteinase 2 coding genes (52_1 and 52_2) (Table S5, Supporting information). Only one of the between-gene epistatic selection signals arose between two SNPs situated in genes with different annotations: between an indel in gene 142 (Fig. S2, Supporting information) and a non-synonymous mutation in gene 39 (Table S4).

When considering pairs of populations in the northern and southern slopes, or at high or low elevations, the highest number of pairs with evidence of epistatic selection arose in the southern populations $(0.41 \%)$ and the lowest number of pairs $(0.24 \%)$ in the low elevation populations (Table 2, Fig. 3 and 4, Fig. S3, Supporting information). Most epistatic interactions also arose between SNPs within genes, with the lowest number of within-gene interactions detected in the southern populations (48\%, Table 2). Most importantly, however, most epistatic interactions that were unique to one of the population pairs were observed between different genes (Table 2). Four unique between-gene epistatic interactions were present in the northern populations: one between genes 52_2 and 98_1, and a small network involving genes 142, 61_2, and 68 (Fig. 4). Notably, gene 68 was connected to each of the other genes via two non-synonymous coding SNPs (Table S4), while gene 61_2 had only synonymous mutations (Table S2). Both genes have important functional roles related to stress response: 61_2 is a member of the heat shock protein 70 family and 68 catalyzes glycolysis (Table S5). The epistatic interaction between genes 142 and 61_2 was also

This article is protected by copyright. All rights reserved. 
Version définitive du manuscrit publiée dans / Final version of the manuscript published in :

Molecular Ecology (2014), DOI: 10.1111/mec.12902

Journal homepage: http:/lonlinelibrary.wiley.com/doi/10.1111/mec.12902/abstract

confirmed in the high-elevation populations (Fig. 3 and 4). One unique within-gene epistatic interaction in gene 50 was observed in the southern and low-elevation populations, including a SNP from a 3'UTR region (Table S4). Gene 50 is a major transcription factor involved in response to abiotic stress and has been shown to respond to cold temperatures (Table S5).

Nineteen unique between-gene epistatic selection signals were observed in the southern populations, and four of them were also observed in the low-elevation populations (Fig. 3 and 4). Thirty SNP pairs in these interactions contained non-synonymous mutations or were located within regulatory regions of genes 39, 52_1, 68, 80, and 155_3 (Table S4). The presence of gene 80 in the gene networks of the southern and low-elevation populations is of particular significance because it regulates stomatal closure (a key trait involved in response to drought) and has been suggested to play a role in dormancy (Table S5). Further, two of the budburst candidate genes (genes 148_1 and 145_2, Table S5) were also present in the gene networks of the southern and low-elevation populations (only gene 148_1 in the latter).

\section{DiscUSSION}

Several recent studies have attempted to detect signatures of selection from candidate gene data in forest trees. This study is based on recently developed candidate genes (Lalagüe et al., 2014) for an ecologically and economically important species, European beech, for which genomic resources are still scarce (see also Müller, 2013; Seifert, 2011). Signatures of selection were investigated at a short geographical scale, where pronounced environmental differences may impose a strong selection pressure. We combined classic $F_{S T}$ outlier methods with a multi-locus approach and detected signatures of directional, homogenizing and

This article is protected by copyright. All rights reserved. 
Version définitive du manuscrit publiée dans / Final version of the manuscript published in :

Molecular Ecology (2014), DOI: 10.1111/mec.12902

Journal homepage: http:/lonlinelibrary.wiley.com/doi/10.1111/mec.12902/abstract

epistatic selection. Loci and genes found under selection often had well-documented functional roles.

\section{$F_{S T}$ outliers}

Despite the small spatial scale investigated and the fact that only four populations were sampled, we nonetheless detected a few $F_{S T}$ outliers, which suggests that the environmental differences that exist between sampling sites influence the adaptive strategies of $F$. sylvatica on Mont Ventoux and that selection can be efficient even when populations are under strong gene flow (Audigeos et al. 2013). Two of the outlier SNPs (in genes 23_1 ad 142) detected in the northern populations are a signature of selection imposed by elevational differences, while the third outlier SNP (in gene 88_1) most likely is a signature of selection imposed by differences between the northern and southern slopes, irrespectively of elevation. Two of the outlier SNPs were detected using a hierarchical model, which also made it possible to detect the imprint of selection along environmental gradients in other forest tree populations (e.g. Alberto et al., 2013b; Mosca et al., 2014).

Candidate gene data are composed of blocks of often tightly linked SNPs. As a result, the assumption of independence between loci imposed by genome scan methods is violated, which potentially leads to elevated rates of false positives (Vilas et al. 2012). While the proportion of linked SNP pairs are negligible when using many genes with few SNPs per gene (e.g. in Alberto et al. 2013b, 105 genes with 2-3 SNPs per gene), our dataset contained 9 SNPs per gene, on average. Following the ideas of Foll \& Gaggiotti (2008) and Eveno et al. (2008), we applied BayeScan at the gene level (using haplotypes as alleles). Our study highlighted the extreme sensitivity of outlier tests to phase reconstruction: some extremely 
Version définitive du manuscrit publiée dans / Final version of the manuscript published in :

Molecular Ecology (2014), DOI: 10.1111/mec.12902

Journal homepage: http:/lonlinelibrary.wiley.com/doi/10.1111/mec.12902/abstract

high Bayes factors were observed in some realizations of the phased dataset (i.e. in some of the posterior samples from PHASE). To avoid over-interpretation, we proposed a model averaging approach, using the median $F_{S T}$ and Bayes factors over several BayeScan runs, and thus averaging over the uncertainty inherent to the estimation of haplotype frequencies.

$F_{S T}$ outlier tests based on haplotypes appear promising, not only because detecting selection using multiallelic markers may increase statistical power (Foll \& Gaggiotti, 2008), but also because such tests can enhance our understanding of how selection operates. Notably, at the SNP level we only detected directional selection, whereas at the gene level, several genes showed unusually low $F_{S T}$ values, thus balancing selection signatures (Fig. 2B). Although none of the genes had a Bayes Factor over 3, the gene 134_2_2 deserves particular attention as Bayes Factors were over 20 in some phase reconstructions (Fig. 2E). Gene 134_2_2 codes for a metallothionein $2 \mathrm{a}$ protein that has a ubiquitous role in stress response in plants (Table S5). Interestingly, gene 23_1, which had one SNP under directional selection, showed a weak signal for balancing selection at the gene level (Fig. 2C). These results suggest that there is more power to detect balancing selection at the gene than at the SNP level, consistently with the success of haplotype based methods for detecting selection (e.g. Fariello et al., 2013). However, the possibility that such balancing selection is, at least partly, an artifact, cannot be excluded. Even though the uncertainty of the phase reconstruction was taken into consideration, we always replaced missing data with the most common haplotype, thus generating haplotypes that are frequent in all populations, which may induce a (true or false) signal of balancing selection. Note that when applying Ohta's method, we do not replace missing data with a best guess haplotype.

This article is protected by copyright. All rights reserved. 
Version définitive du manuscrit publiée dans / Final version of the manuscript published in :

Molecular Ecology (2014), DOI: 10.1111/mec.12902

Journal homepage: http:/lonlinelibrary.wiley.com/doi/10.1111/mec.12902/abstract

\section{Epistatic selection}

Selection on epistatic deviations has long been considered negligible due to its transitory nature: the elevated frequency of co-occurrence of beneficial allele combinations (i.e. haplotypes) is expected to be continuously broken down by recombination (Griffing 1960). However, past studies ignored that this statistical effect of selection (visible through the build-up of LD) may be maintained because most genes do not act independently, but as members of complex gene interaction networks (so-called functional epistasis; Lehner 2011, Hansen 2013, Mackay, 2014). Consequently, on the one hand, it is important to realize that Ohta's test can principally capture the signature of recent selection. In fact, Le Corre \& Kremer (2003) and Storz and Kelly (2008) also argued that recent adaptation can be detected with the between population component of LD (i.e. with Ohta's $D_{S T}$ ). However, on the other hand, if Ohta's test is applied to a set of loci that are either directly or indirectly connected (e.g. play a role in the same metabolic network), the chances of detecting "older" epistatic selection may be increased. This advantage does not apply to single-locus methods of detection of local adaptation using Ohta's $D_{S T}$ (as e.g. in Ma et al. 2010).

Ohta's test (1982) has been relatively little used in the past (but see e.g. for forest trees by Cheng et al. 2001; Fernández-López \& Monteagudo, 2010), and, more strikingly, most studies found no signal of epistatic selection (but see Black et al. 2008). We argue that we were able to detect epistatic selection because conditions were extremely favorable for the test. First, it has been estimated that F. sylvatica populations re-colonized Mont Ventoux about five generations ago (Lander et al. 2011), thus we were studying a population of recent origin, exposed to sharp environmental differences only in the past few generations. Second, our genetic data comprise functionally related candidate genes (Lalagüe et al. 2014, Tables S1 and S5), which could have favored the build-up and maintenance of LD due to epistatic

This article is protected by copyright. All rights reserved. 
Version définitive du manuscrit publiée dans / Final version of the manuscript published in :

Molecular Ecology (2014), DOI: 10.1111/mec.12902

Journal homepage: http:/lonlinelibrary.wiley.com/doi/10.1111/mec.12902/abstract

selection. The frequency of between- and within-gene epistatic interactions seems to further corroborate this idea. Although we found that most epistatic selection signals arose between SNPs within-genes, those unique to northern, southern, high-, or low-elevation populations arose principally between SNPs from different genes. Many known examples of within-gene epistasis involve mutations that act in a multiplicative manner (Lehner 2011), thus it seems plausible that they have been advantageous in all environments. In contrast, most systematically mapped epistatic interactions that involve mutations between different genes bring new functionality that may only be advantageous in a particular environment (Lehner 2011).

\section{Evidences of recent selection in F. sylvatica on Mont Ventoux}

By combining $F_{S T}$ outlier methods with a multi-locus test of epistatic selection, we identified several $F$. sylvatica candidate genes that may have been under recent, climate-induced selection. A remarkable difference was observed between the northern (and high-elevation) and southern (and low-elevation) populations in all results that may be explained by recent population history. While the northern populations had a relatively high overall $F_{S T}$ (Fig. S1), possessed most of the detected $F_{S T}$ outliers and only a few unique epistatic interactions, the southern populations had a low overall $F_{S T}$ (Fig. S1), no $F_{S T}$ outliers, but many unique between gene epistatic interactions. These results suggest that conditions for divergent selection have been more favorable in northern populations. Further, one of the $F_{S T}$ outliers, gene 142 (Fig. 2A and D, Appendix S1), also played a central role in the epistatic interaction network of northern populations (Fig. 4). Results of Ohta's test from the southern populations have to be considered with caution because the sample size to estimate haplotype frequencies is small in the southern populations (25 diploids). However, comfortingly, the numerous epistatic interactions detected were confirmed over many different possible phase 
Version définitive du manuscrit publiée dans / Final version of the manuscript published in :

Molecular Ecology (2014), DOI: 10.1111/mec.12902

Journal homepage: http:/lonlinelibrary.wiley.com/doi/10.1111/mec.12902/abstract

reconstructions, and involved well-documented bud-burst candidate genes (Table S5).

Further, the SL population experienced the most recent population expansion of all four populations (Lander et al. 2011), generating the most favorable conditions for Ohta's test. Additionally, the SL population may have been re-colonized both from the eastern and western remnant populations of Mont Ventoux, thus potentially generating favorable allele combinations. Finally, and overall, most loci detected to be under selection were involved in the "reactive oxygen species" (ROS) stress response (Table S5), which opens new perspectives for understanding the functional roles of these loci.

\section{Sampling strategies for future studies}

Our study illustrates that different selection mechanisms may act simultaneously in natural populations, such as directional, homogenizing, and epistatic selection. Detecting different types of selection, however, may require different sampling strategies. Most studies aimed at detecting local adaptations with $F_{S T}$ outlier methods or allele frequency clines, generally prefer sampling many populations along an environmental gradient at the expense of having rather few samples per populations (10-15 individuals). In contrast, for Ohta's (1982) test, one has to estimate haplotype frequencies, which requires more individuals than estimating allele frequencies. We suggest that for efficiently combining $F_{S T}$ outlier/clinal methods with Ohta's (1982) test, an appropriate compromise would be to sample many populations along an environmental gradient with few individuals, but sampling more individuals at the extremes for a test of epistatic selection or other haplotype based methods.

This article is protected by copyright. All rights reserved. 
Version définitive du manuscrit publiée dans / Final version of the manuscript published in :

Molecular Ecology (2014), DOI: 10.1111/mec.12902

Journal homepage: http:/lonlinelibrary.wiley.com/doi/10.1111/mec.12902/abstract

\section{Conclusions}

Two different ideas seem to dominate the current methodological developments for detecting selection in natural populations: first, integrating environmental and ecological data into population and landscape genomics tools (Schoville et al. 2012), and, second, shifting from single locus to more realistic multi-locus models of evolution, such as polygenic and epistatic selection (e.g. Pritchard et al. 2010; Le Corre \& Kremer, 2012; Fu \& Akey, 2013; Pannell \& Fields, 2014). This study illustrates that combining $F_{S T}$ outlier methods and Ohta's test can be fruitful for gaining a deeper understanding of the mechanisms driving selection. Testing for epistatic selection is particularly relevant to candidate gene data, because one can make use of the, often neglected, functional genomic information inherent to this type of data. Finally, we recommend testing for polygenic and epistatic selection using candidate gene data from haploid tissue (easily accessible from conifer megagametophytes), hence removing the high uncertainty relative to haplotype inference in diploid organisms.

\section{REFERENCES}

Alberto, F.J., Aitken, S.N., Alía, R., Gonzàlez-Martinez, S.C., Hänninen, H., Kremer, A., Lefèvre, F., Lenormand, T., Yeaman, S., Whetten, R., \& Savolainen, O. (2013a) Potential for evolutionary responses to climate change: evidence from tree populations. Global Change Biology, 19, 1645-1661.

Alberto, F.J., Derory, J., Boury, C., Frigerio, J.-M., Zimmermann, N.E., \& Kremer, A. (2013b) Imprints of natural selection along environmental gradients in phenology-related genes of Quercus petraea. Genetics, 195, 495-512.

Altschul, S.F., Gish, W., Miller, W., Myers, E.W., \& Lipman, D.J. (1990) Basic local alignment search tool. Journal of Molecular Biology, 215, 403-410.

Audigeos, D., Brousseau, L., Traissac, S., Scotti-Saintagne, C. \& Scotti, I. (2013) Molecular divergence in tropical tree populations occupying environmental mosaics. Journal of Evolutionary Biology, 26, 529-544

Beaumont, M.A. \& Nichols, R.A. (1996) Evaluating loci for use in the genetic analysis of population structure. Proceedings of the Royal Society of London B, 263, 1619-1626.

Black, W.C., Gorrochetegui-Escalante, N., Randle, N.P., \& Donnelly, M.J. (2008). The Yin and Yang of linkage disequilibrium: mapping of genes and nucleotides conferring

This article is protected by copyright. All rights reserved. 
Version définitive du manuscrit publiée dans / Final version of the manuscript published in :

Molecular Ecology (2014), DOI: 10.1111/mec.12902

Journal homepage: http:/lonlinelibrary.wiley.com/doi/10.1111/mec.12902/abstract

insecticide resistance in insect disease vectors. In Transgenesis and the Management of Vector-Borne Disease, pp. 71-83. Springer, New York, USA

Bresson, C.C., Vitasse, Y., Kremer, A., \& Delzon, S. (2012) To what extent is altitudinal variation of functional traits driven by genetic adaptation in European oak and beech? Tree Physiology, 31, 1164-1174.

Chen, J., Källman, T., Ma, X., Gyllenstrand, N., Zaina, G., Morgante, M., Bousquet, J., Eckert, A., Wegrzyn, J., Neale, D., Lagercrantz, U., \& Lascoux, M. (2012) Disentangling the roles of history and local selection in shaping clinal variation of allele frequencies and gene expression in Norway spruce (Picea abies). Genetics, 191, 865-881.

Cheng, Y.-P., Chien, C.-T., Chen, H.-W., \& Lin, T.-P. (2001) Allozyme variation of Cyclobalanopsis championii (Fagaceae), a narrowly distributed species in southern Taiwan. Journal of Heredity, 92, 65-70.

De Mita, S., Thuillet, A.-C., Gay, L., Ahmadi, N., Manel, S., Ronfort, J., \& Vigouroux, Y. (2013) Detecting selection along environmental gradients: analysis of eight methods and their effectiveness for outbreeding and selfing populations. Molecular Ecology, 22, 1383-1399.

Eveno, E., Collada, C., Guevara, M.A., Leger, V., Soto, A., Diaz, L., Leger, P., GonzalezMartinez, S.C., Cervera, M.T., Plomion, C., \& Garnier-Gere, P.H. (2008) Contrasting patterns of selection at Pinus pinaster Ait. drought stress candidate genes as revealed by genetic differentiation analyses. Mol Biol Evol, 25, 417-437.

Excoffier, L., Hofer, T., \& Foll, M. (2009) Detecting loci under selection in a hierarchically structured population. Genetics 103, 285-298.

Excoffier, L., Smouse, P.E., \& Quattro, J.M. (1992) Analysis of Molecular Variance inferred from metric distance among DNA haplotypes: application to human mitochondrial DNA restriction data. Genetics, 131, 479-191.

Fariello, M.I., Boitard, S., Naya, H., SanCristobal, M., \& Servin, B. (2013) Detecting signatures of selection through haplotype differentiation among hierarchically structured populations. Genetics, 193, 929-941.

Fernández-López, J. \& Monteagudo, A.B. (2010) Genetic structure of Spanish wild populations of Castanea sativa as measured by isozyme analysis. Forest Systems, 19(2), 156-169.

Foll, M. \& Gaggiotti, O. (2008) A genome-scan method to identify selected loci appropriate for both dominant and codominant markers: a Bayesian perspective. Genetics, 180, 977993.

Fu, W. \& Akey, J.M. (2013) Selection and Adaptation in the Human Genome. Annual Review of Genomics and Human Genetics, 14, 467-489.

Gauzëre, J., Klein, E.K., \& Oddou-Muratorio, S. (2013) Ecological determinants of mating system within and between three Fagus sylvatica populations along an elevational gradient. Molecular Ecology, 22, 5001-15.

Griffing, B. (1960) Theoretical consequences of truncation selection based on the individual phenotype. Australian Journal of Biological Sciences, 13, 307-343.

Hansen, M.M., Olivieri, I., Waller, D.M., Nielsen, E.E., \& Group, T.G.W. (2012) Monitoring adaptive genetic responses to environmental change. Molecular Ecology, 21, 1311-1329.

Hansen, T.F. (2013) Why epistasis is important for selection and adaptation. Evolution, 67, 3501-3511.

This article is protected by copyright. All rights reserved. 
Version définitive du manuscrit publiée dans / Final version of the manuscript published in :

Molecular Ecology (2014), DOI: 10.1111/mec.12902

Journal homepage: http:/lonlinelibrary.wiley.com/doi/10.1111/mec.12902/abstract

Hudson, R.R. (2002) Generating samples under a Wright-Fisher neutral model of genetic variation. Bioinformatics, 18, 337-338.

Jump, A. S., Hunt, J. M., Martinez-Izquierdo, J. A. \& Penuelas, J. (2006) Natural selection and climate change: temperature-linked spatial and temporal trends in gene frequency in Fagus sylvatica. Molecular Ecology, 15, 3469-3480.

Körner, C. (2007) The use of 'altitude' in ecological research. Trends in Ecology \& Evolution, 22, 569-574.

Kremer, A., Abbott, A., Carlson, J., Manos, P., Plomion, C., Sisco, P., Staton, M., Ueno, S., \& Vendramin, G. (2012) Genomics of Fagaceae. Tree Genetics \& Genomes, 8, 583-610.

Kujala, S. \& Savolainen, O. (2012) Sequence variation patterns along a latitudinal cline in Scots pine (Pinus sylvestris): signs of clinal adaptation? Tree Genetics \& Genomes, $\mathbf{8}$, 1451-1467.

Lalagüe, H., Csillery, K., Oddou-Muratorio, S., Safrana, J., de Quattro, S., Fady, B., Gonzalez-Martinez, S.C., \& Vendramin, G.G. (2014) Nucleotide diversity and linkage disequilibrium at 58 stress-response and phenology candidate genes in an European beech (Fagus sylvatica L.) population from south-eastern France. Tree Genetics and Genome, 10, 15-26.

Lander, T.A., Oddou-Muratorio, S., Prouillet-Leplat, H., \& Klein, E.K. (2011) Reconstruction of a beech population bottleneck history using archival demographic information and Bayesian analysis of genetic data. Molecular Ecology, 20, 5182-5196.

Le Corre, V. \& Kremer, A. (2003) Genetic variability at neutral markers, quantitative trait loci and trait in a subdivided population under selection. Genetics, 164, 1205-1219.

Le Corre, V. \& Kremer, A. (2012) The genetic differentiation at quantitative trait loci under local adaptation. Molecular Ecology, 21, 1548-1566.

Lehner, B. (2011) Molecular mechanisms of epistasis within and between genes. Trends in Genetics, 27, 323-331.

Li, N. \& Stephens, M. (2003) Modeling linkage disequilibrium and identifying recombination hotspots using single-nucleotide polymorphism data. Genetics 165 2213-2233

Lotterhos, K.E. \& Whitlock, M.C. (2014) Evaluation of demographic history and neutral parameterization on the performance of FST outlier tests. Molecular Ecology, 23, 21782192.

Ma, X.-F., Hall, D., Onge, K.R.S., Jansson, S., \& Ingvarsson, P.K. (2010) Genetic Differentiation, Clinal variation and phenotypic associations with growth cessation across the Populus tremula photoperiodic pathway. Genetics, 186, 1033-1044.

Mackay, T.F.C. (2014) Epistasis and quantitative traits: using model organisms to study gene-gene interactions. Nat Rev Genet 15, 22-33.

Magri, D., Vendramin, G.G., Comps, B., Dupanloup, I., Geburek, T., Gomory, D., Latalowa, M., Litt, T., Paule, L., Roure, J.M., Tantau, I., van der Knaap, W.O., Petit, R.J., \& de Beaulieu, J.-L. (2006) A new scenario for the Quaternary history of European beech populations: palaeobotanical evidence and genetic consequences. New Phytologist, 171, 199-221.

Mikola, J. (1982) Bud-set phenology as an indicator of climatic adaptation of Scots pine in Finland. Silva Fennica, 16, 178-182.

This article is protected by copyright. All rights reserved. 
Mosca, E., Gonzàlez-Martìnez, S.C., \& Neale, D.B. (2014) Environmental versus geographical determinants of genetic structure in two subalpine conifers. New Phytologist, 201, 180-192.

Müller, M. (2013) A candidate gene-based association study to investigate potentially adaptive genetic variation in European beech (Fagus sylvatica L.), Georg-AugustUniversität Göttingen, Göttingen, Germany.

Neale, D.B. \& Kremer, A. (2011) Forest tree genomics: growing resources and applications. Nat Rev Genet, 12, 111-122.

Ohta, T. (1982 ) Linkage disequilibrium due to random genetic drift in finite subdivided populations. Proceedings of the National Academy of Sciences 79 1940-1944

Pannell, J.R. \& Fields, P.D. (2014) Evolution in subdivided plant populations: concepts, recent advances and future directions. New Phytologist, 201, 417-432.

Pluess, A.R. \& Weber, P. (2012) Drought-Adaptation Potential in Fagus sylvatica: Linking Moisture Availability with Genetic Diversity and Dendrochronology. PLoS ONE, 7(3): e33636.

Pritchard, J.K., Pickrell, J.K., \& Coop, G. (2010) The genetics of human adaptation: hard sweeps, soft sweeps, and polygenic adaptation. Current Biology, 20, R208-R215.

Savolainen, O. \& Pyhäjärvi, T. (2007) Genomic diversity in forest trees. Current Opinion in Plant Biology, 10, 162-167.

Schoville, S.D., Bonin, A., François, O., Lobreaux, S., Melodelima, C., \& Manel, S. (2012) Adaptive genetic variation on the landscape: methods and cases. Annual Review of Ecology, Evolution, and Systematics, 43, 23-43.

Seifert, S. (2011) Variation of candidate genes related to climate change in European beech (Fagus sylvatica L.). Ph.D. Dissertation., Georg-August-University, Göttingen, Germany

Seifert, S., Vornam, B., \& Finkeldey, R. (2012) DNA sequence variation and development of SNP markers in beech (Fagus sylvatica L.). European Journal of Forest Research, 131, 1761-1770.

Stephens, M. \& Donnelly, P. (2003) A comparison of Bayesian methods for haplotype reconstruction from population genotype data. The American Journal of Human Genetics, 73, 1162-1169.

Storz, J.F. \& Kelly, J.K. (2008) Effects of spatially varying selection on nucleotide diversity and linkage disequilibrium: insights from deer mouse globin genes. Genetics, 180, $367-$ 379.

Vilas, A., Pérez-Figueroa, A., \& Caballero, A. (2012) A simulation study on the performance of differentiation-based methods to detect selected loci using linked neutral markers. Journal of Evolutionary Biology, 25, 1364-1376.

Vitasse, Y., Delzon, S., Bresson, C.C., Michalet, R., \& Kremer, A. (2009) Altitudinal differentiation in growth and phenology among populations of temperate-zone tree species growing in a common garden. Canadian Journal of Forest Research, 39, 12591269.

Weir, B.S. (1996) Genetic Data Analysis II., Sunderland, Mass.

Weir, B.S. \& Cockerham, C.C. (1984) Estimating F-statistics for the analysis of population structure. Evolution, 38, 1358-1370.

This article is protected by copyright. All rights reserved. 
Version définitive du manuscrit publiée dans / Final version of the manuscript published in :

Molecular Ecology (2014), DOI: 10.1111/mec.12902

Journal homepage: http:/lonlinelibrary.wiley.com/doi/10.1111/mec.12902/abstract

\section{ACKNOWLEDGEMENTS}

We thank Pauline Garnier-Géré for her help with the cleaning and the analyses of candidate gene sequences, and Andrea Pluess for help and comments on our results and analyses. We thank Norbert Turion, Olivier Gilg, Frank Rei (INRA-UEFM) for fieldwork, Marianne Corréard for GIS work, and Sara Torre and Federico Sebastiani for their help in the lab. All authors were supported by the EU Network of Excellence EvolTree (GOCE-016322). This research was also funded by the ERA-Net BiodivERsA, with the national funders ANR (France) and MINECO (Spain), part of the 2008 and 2012 BiodivERsA call for research proposals (projects LinkTree and TipTree). GGV was also supported by by the Italian MIUR project Biodiversitalia (RBAP10A2T4). HL, SOM and BF were supported by INRA-EFPA project “Innovant 2010”. SCGM was supported by AdapCon project (CGL2011-30182-C0201).

\section{DATA ACCESSIBILITY}

The raw, imputed and phased genotype datasets (546 SNPs) have been archived in DRYAD : doi:10.5061/dryad.dg4hq.

\section{FiguRE LEGENDS}

Fig. 1 Map of the four sampling sites situated on the northern and southern slopes on Mont Ventoux, France.

Fig. $2 F_{S T}$ outlier SNPs and genes detected with Bayescan. A outlier detection at the level of SNPs from 52 candidate genes and two pairs of populations situated at the northern and southern slopes of Mont Ventoux. B outlier detection at the level of candidate genes using the

This article is protected by copyright. All rights reserved. 
Version définitive du manuscrit publiée dans / Final version of the manuscript published in :

Molecular Ecology (2014), DOI: 10.1111/mec.12902

Journal homepage: http:/lonlinelibrary.wiley.com/doi/10.1111/mec.12902/abstract

phased dataset, where each gene is treated as a multiallelic locus, with the inferred haplotypes as alleles. Median $F_{S T}$ and median Bayes Factors were calculated from $10^{3}$ independent BayeScan runs each on a different realization of best-guess haplotype sample. C-F $F_{S T}$ and Bayes Factors in the $10^{3}$ best-guess haplotype samples at the four genes that were outliers either at the SNP (C-D) or gene level (E-F).

Fig. 3. Heatmap of evidence for epistatic selection between candidate genes from A: the northern (upper triangle) and southern (lower triangle) slope, and B: high (upper triangle) and low (lower triangle) elevational sites of Mont Ventoux. Colors indicate the number of SNP pairs within genes that passed Ohta's test for epistatic selection (i.e. $\mathrm{D}_{\mathrm{ST}}{ }^{2}<\mathrm{D}_{\mathrm{IS}}{ }^{2}$ and $\mathrm{D}_{\mathrm{IS}}^{\prime}{ }^{2}<$

$\left.\mathrm{D}_{\mathrm{ST}}{ }^{2}\right)$. The redder the color of the cell is the more SNP pairs are under epistatic selection between a pair of genes. The diagonal shows the within gene epistatic effects averaged over the northern and southern (A) or higher and lower (B) populations. White cells indicate missing data (i.e. Ohta's test was not performed). See Figure S1 for a heatmap between all individual SNP pairs.

Fig. 4 Networks of genes constructed based on evidence from Ohta's test for the northern, southern, higher, and lower population pairs. Only between-gene gene epistatic interactions are shown. Black edges indicate interactions that were present in all four populations, while red edges indicate those specific to the population pairs.

\section{SUPPORTING INFORMATION}

Additional supporting information may be found in the online version of this article.

Appendix S1 Sensitivity analyses of $F_{S T}$ outlier tests to population demography.

This article is protected by copyright. All rights reserved. 
Version définitive du manuscrit publiée dans / Final version of the manuscript published in :

Molecular Ecology (2014), DOI: 10.1111/mec.12902

Journal homepage: http:/lonlinelibrary.wiley.com/doi/10.1111/mec.12902/abstract

Appendix S2 Sensitivity analyses of $F_{S T}$ outlier tests to the minor allelic frequency (MAF) criterion.

Table S1 Annotations and GeneBank accession numbers of the 53 studied candidate genes.

Table S2 Summary of the open reading frames (ORF) and the intron-exon boundaries analysis for each of the 53 Fagus sylvatica candidate genes.

Table S3 Global AMOVA tests of genetic differentiation at Fagus sylvatica candidate genes at the SNP and gene levels.

Table S4 SNP pairs showing evidence of epistatic selection in at least one of the population pairs or across all populations (All) and involving at least one SNP conding for a nonsynonymous mutation or situated in a 3'UTR region.

Table S5 Functional interpretation of loci showing evidence of selection (directional, balancing or epistatic).

Fig. S1 Distribution of $F_{S T}$-values at 53 candidate genes and 446 SNPs.

Fig. S2 The sequences of all different haplotypes of gene 142 and their frequencies in the different populations.

This article is protected by copyright. All rights reserved. 
Version définitive du manuscrit publiée dans / Final version of the manuscript published in :

Molecular Ecology (2014), DOI: 10.1111/mec.12902

Journal homepage: http:/lonlinelibrary.wiley.com/doi/10.1111/mec.12902/abstract

Fig. S3 Heatmap of evidence for epistatic selection between SNPs of $F$. sylvatica candidate gene fragments. A: between populations on the northern (upper triangle) and southern (lower triangle) slopes. B: A: between populations at High (upper triangle) and Low (lower triangle) elevations.

\section{TABLES}

Table 1 Climate of the four sampling sites as in situ measures averaged from 2007 to 2013.

Climatic data include the mean (Tmean), maximum (Tmax) and minimum (Tmin) yearly temperature and the mean (RHmean\%) and minimum (RHmin\%) relative humidity.

\begin{tabular}{llllllll}
\hline \hline & Elevation & Tmean & Tmax & Tmin & RHmean & RHmax & RHmin \\
Population & $(\mathrm{m})$ & $\left({ }^{\circ} \mathrm{C}\right)$ & $\left({ }^{\circ} \mathrm{C}\right)$ & $\left({ }^{\circ} \mathrm{C}\right)$ & $(\%)$ & $(\%)$ & $(\%)$ \\
\hline North Low & 995 & 9.8 & 13.4 & 6.8 & 74 & 86.4 & 58.6 \\
North & & & & & 87.5 & \\
High & 1340 & 7.3 & 10.3 & 4.6 & 75.5 & & 59.8 \\
South Low & 895 & 10.8 & 16.1 & 6.6 & 69.6 & 85.1 & 52.3 \\
South & & & & & & \\
High & 1517 & 6.5 & 10.5 & 3.3 & 73.1 & & 56.5 \\
\hline \hline
\end{tabular}

This article is protected by copyright. All rights reserved. 
Version définitive du manuscrit publiée dans / Final version of the manuscript published in :

Molecular Ecology (2014), DOI: 10.1111/mec.12902

Journal homepage: http:/lonlinelibrary.wiley.com/doi/10.1111/mec.12902/abstract

Table 2 Summary of Ohta's test results. The upper part shows the number of realized pairwise comparisons, and the number of SNP pairs that passed one or the two conditions of the test. In the lower part, "Confirmed" stands for the number of SNP pairs where the test results were confirmed in at least $95 \%$ of the datasets sampled from the posterior distributions of the haplotypes generated by PHASE.

\begin{tabular}{|c|c|c|c|c|c|}
\hline Pairs of populations & North & South & High & Low & All \\
\hline \multicolumn{6}{|c|}{ Ohta's test (number of pairs) } \\
\hline Number of realized pairwise comparisons & 79,955 & 76,794 & 72,998 & 87,834 & 85,036 \\
\hline $\mathrm{D}^{2} \mathrm{ST}_{\mathrm{T}}<\mathrm{D}_{\mathrm{IS}}^{2}$ & 455 & 814 & 603 & 758 & 457 \\
\hline $\mathrm{D}^{2}{ }_{\text {IS }}<\mathrm{D}^{2}{ }_{\mathrm{ST}}$ & 299 & 424 & 290 & 372 & 227 \\
\hline $\mathrm{D}^{2}{ }_{\mathrm{ST}}<\mathrm{D}^{2}{ }_{\mathrm{IS}}$ and $\mathrm{D}^{2}{ }_{\mathrm{IS}}<\mathrm{D}^{2}{ }_{\mathrm{ST}}$ & 287 & 410 & 278 & 333 & 222 \\
\hline Number of confirmed pairs & 228 & 318 & 184 & 211 & 199 \\
\hline \multicolumn{6}{|c|}{ Confirmed SNP pairs within-genes (percent of pairs) } \\
\hline Overall & 68 & 48 & 72 & 77 & 79 \\
\hline Unique to the sub-populations & 26 & 12 & 16 & 58 & NA \\
\hline
\end{tabular}

This article is protected by copyright. All rights reserved. 


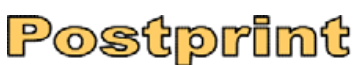

Version définitive du manuscrit publiée dans / Final version of the manuscript published in :

Molecular Ecology (2014), DOI: 10.1111/mec.12902

Journal homepage: http:/lonlinelibrary.wiley.com/doi/10.1111/mec.12902/abstract
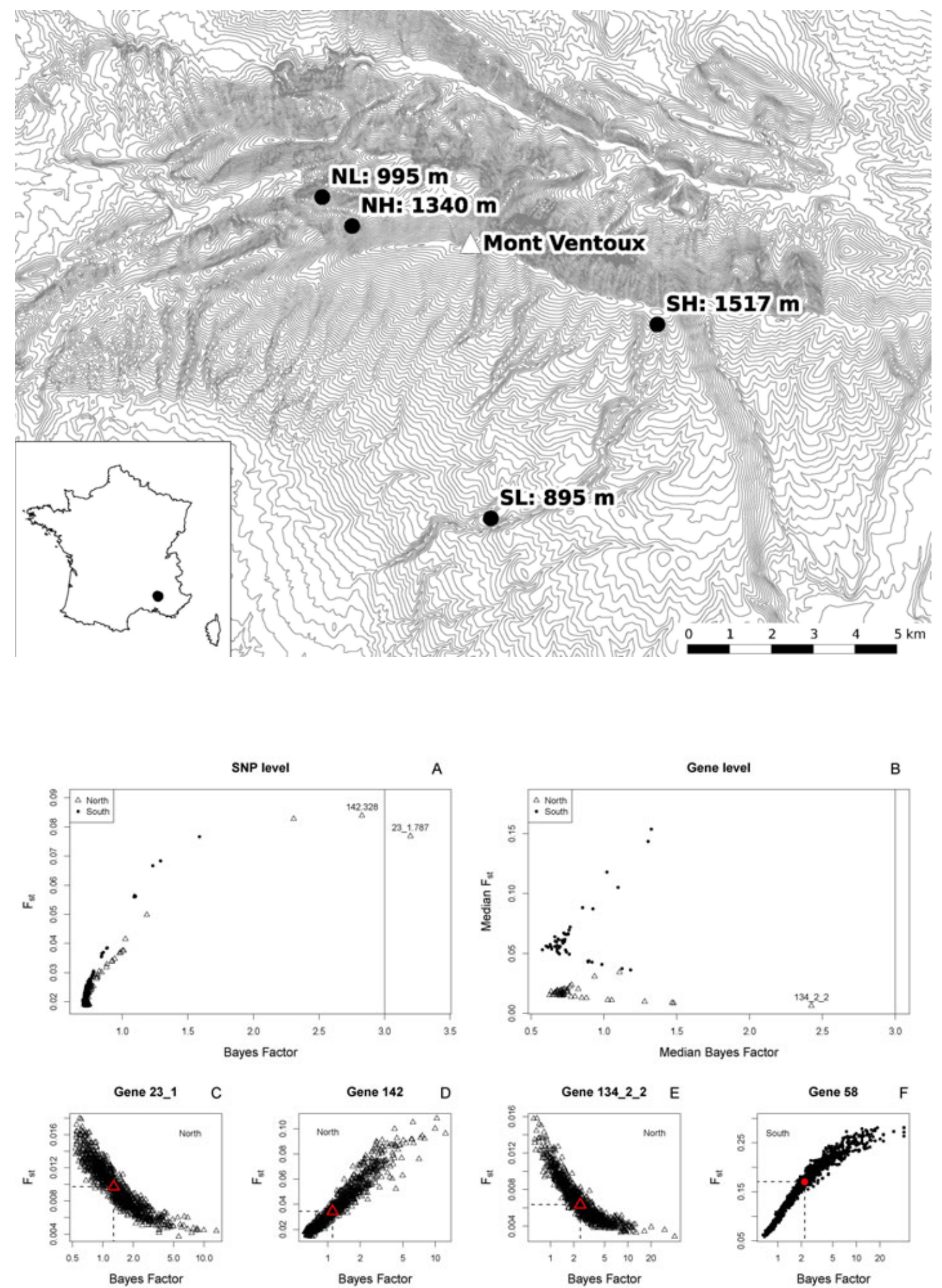

This article is protected by copyright. All rights reserved. 


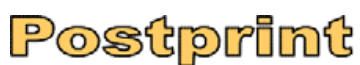

Version définitive du manuscrit publiée dans / Final version of the manuscript published in :

Molecular Ecology (2014), DOI: 10.1111/mec.12902

Journal homepage: http:/lonlinelibrary.wiley.com/doi/10.1111/mec.12902/abstract
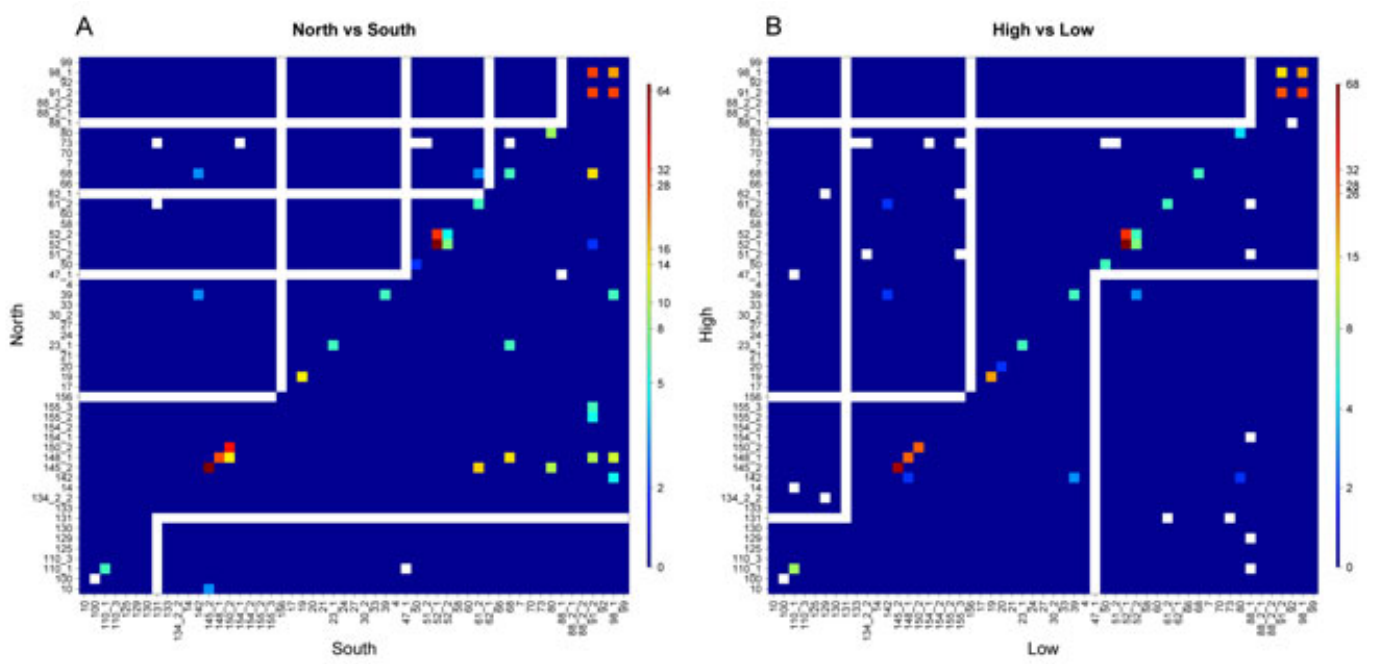

North
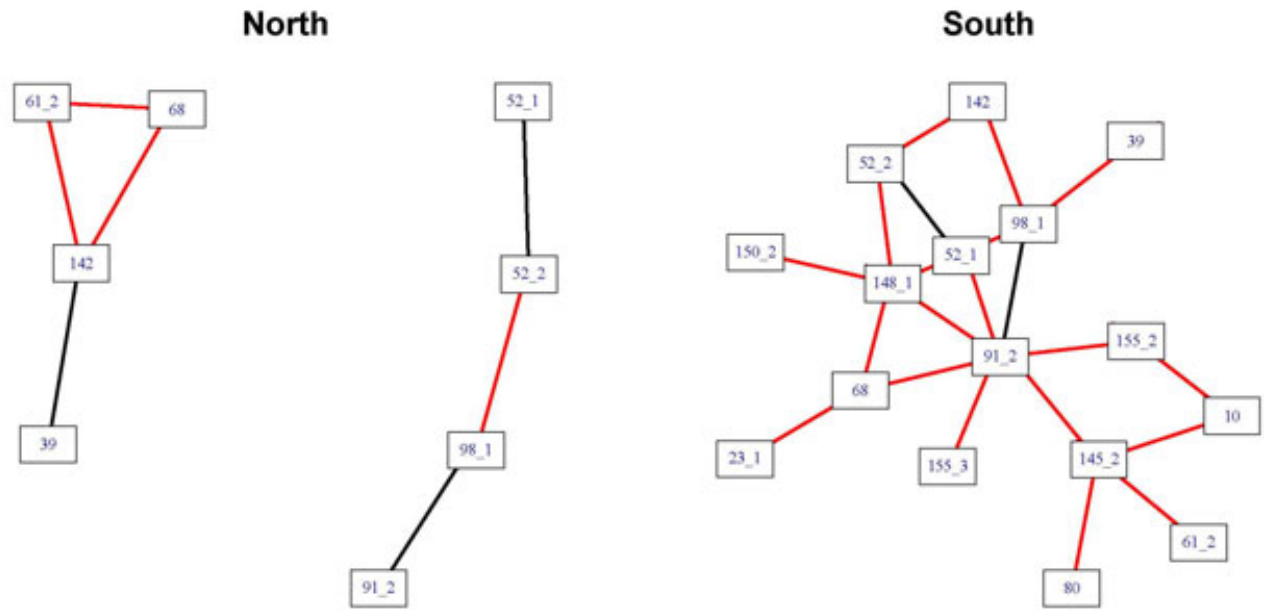

High

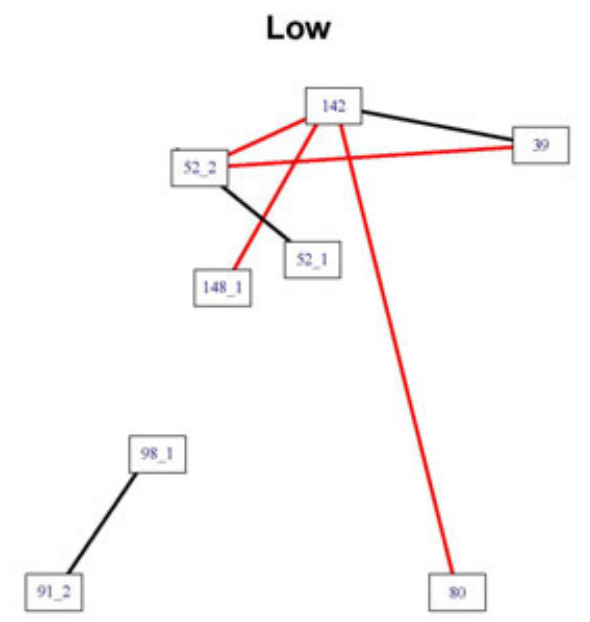

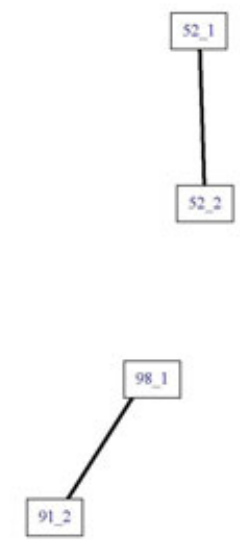

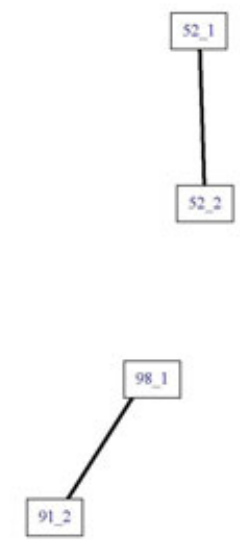

This article is protected by copyright. All rights reserved. 